\title{
Significance of Catalyst Terminologies in Management Publications
}

\author{
Mohd Ridzuan Nordin', Haizal Hussin² \\ 1Faculty of Technology Management and Technopreneurship, 2Faculty of Mechanical Engineering \\ Universiti Teknikal Malaysia Melaka, Melaka, Malaysia
}

\begin{abstract}
The article report on the findings of study on the significance of catalyst related terms used in management publications. This study adopted the qualitative research methods using the content analysis of publications containing catalyst related term such as catalysts, catalytic leader and organisational catalyst. Catalyst related terms are being used to describe organisation related transformations. The most common reactants are Organisation, Process and Follower. The most commonly used catalysts are Process and Leader. This illustrate the importance of process improvement and leadership in driving organisation improvement. The findings indicate the significance of catalyst related terms in management publications to describe organisational transformation.
\end{abstract}

\section{INTRODUCTION}

Catalyst terminologies (terms) occasionally appears in management publications. They were used to indicate effort to speed up change [1],[2],[3] or transformation process such as innovation [4], social development [5] and learning [6]. The terms were also use to discuss a style of leadership [7],[8]. The term Catalytic Mechanism is also used for initiative that leads toward competitive advantage for organisation [9],[10].

Transformation of one chemical entity (reactant) to another take place through chemical reaction [11]. The speed of the reaction is enhanced by catalyst. Without catalyst, reactions happen through the occasional collision among the reacting molecules having collision energy above certain threshold value. The catalyst anchored the reacting molecule through adsorption, activating it, and also lowered the threshold energy value for reaction to take place. This allow more reactants to form the product. The product would then desorb, returning the catalyst to its original form to be adsorbed by other reactant molecules. Ideally catalyst will remain unchanged. In practice the effectiveness of catalyst decreases with time due to physical and chemical changes.

The search for 'catalyst' to speed up organisational related transformation is also of great interest. As in chemical reaction, the desired outcome could be achieved in a more cost-effective manner. The presence of catalyst related terms in management writings may indicate the speeding up of transformation. It may also indicate the application of chemical catalytic concepts in the way organisational related transformation are done. Moreover, the mechanics of chemical catalysis may be transferable to the management field to elucidate the potential of organisation catalysts to catalyse organisational change.

This article shall report on the significance of catalytic related terms used in management publications such as journal paper, corporate document and research theses.

\section{METHODOLOGY}

This study adopted the qualitative research methods using the content analysis of publications obtained from the internet using search engines with catalyst related term such as management catalysts, catalytic leader and organisational catalyst.

A total of 101 publications in the form of journal paper, corporate document, working paper and others were collected for analysis. Content analysis of the documents were done using the summative content analysis techniques [12]. This is followed by the latent content analysis that involve interpreting how the catalytic terms were used in the relevant paragraphs and section analysed.

The presence of catalyst related terms in the title and throughout the document was analysed. The identity of the catalyst and the reactant were identified. The role of the 'catalyst' in facilitating change will also be discussed.

\section{RESULTS AND DISCUSSION}

\subsection{Presence of Catalyst Related Terms}

A total of 101 documents containing Catalyst related term were analysed as presented in Table 1 .

The catalyst related terms found present in these documents were catalyst, catalytic, catalyse and catalysis. The terms used could be divided into three categories being i. to indicate the speeding up of transformation such as Investment Catalyst, Social Catalyst and Communication Catalyst ii. to indicate the special impact of an initiative, Catalytic Mechanism and iii. to indicate the special role of Leaders, Catalytic Leaders.

Forty-four of these publications have the catalyst related terms in the title and 10 of them have these terms only in the title. The frequencies of which the terms appear in the document range from a minimum of 1 to a maximum of 160 .

\begin{tabular}{|c|c|c|c|}
\hline No & Categories & Abbrev. & Total \\
\hline 1 & Academic Papers & AP & 9 \\
\hline 2 & Journal Papers & JP & 28 \\
\hline 3 & Corporate Documents & CD & 29 \\
\hline 4 & Working Paper & WP & 13 \\
\hline 5 & Book Chapter & BC & 9 \\
\hline 6 & Conference Paper & CP & 5 \\
\hline 7 & Thesis & TD & 8 \\
\hline
\end{tabular}

Table 1 Categories of Document Analysed 


\subsection{Catalyst and Reactants}

The distribution of 'Catalyst' in the document studied are tabulated in Table 2. Process and Leadership are the two frequently used 'Catalyst' for organisational transformation.

\begin{tabular}{|c|c|c|c|}
\hline No & Catalyst & Abbrev. & $\%(\mathrm{~N}=94)$ \\
\hline 1 & Leadership & CL & $39 \%$ \\
\hline 2 & Process & CP & $47 \%$ \\
\hline 3 & Skills & CS & $7 \%$ \\
\hline 4 & Organisation & CO & $4 \%$ \\
\hline 5 & Technologies & CT & $3 \%$ \\
\hline
\end{tabular}

Table 2 Distribution of Catalysts

The distribution of 'Reactant' transforming under the influence of the 'Catalyst' are given in Table 3. Organisation is the most frequent reactants followed by Process.

\begin{tabular}{|c|c|c|c|}
\hline No & Reactant & Abbrev. & $\%(\mathrm{~N}=94)$ \\
\hline 1 & Follower & RF & $11 \%$ \\
\hline 2 & Process & RP & $27 \%$ \\
\hline 3 & Skills & RS & $11 \%$ \\
\hline 4 & Organisation & RO & $33 \%$ \\
\hline 5 & Not Identified & RG & $19 \%$ \\
\hline
\end{tabular}

Table 3 Distribution of 'Reactants'

The distribution of 'Catalyst' in the different publications are given in Table 4 while that of 'Reactants' are given in Table 5. Process and Leaders are the two most commonly assigned catalyst. As for the 'Reactants', Process and Organisation are the two most commonly assigned reactants.

\begin{tabular}{|c|c|c|c|}
\hline No & Catalyst & JP (N=24) & CD (N=27) \\
\hline 1 & Leaders & $33 \%$ & $33 \%$ \\
\hline 2 & Process & $58 \%$ & $56 \%$ \\
\hline 3 & Skills & $9 \%$ & $0 \%$ \\
\hline 4 & Organisation & $0 \%$ & $11 \%$ \\
\hline
\end{tabular}

Table 4 Distribution of 'catalysts' in different publication

\begin{tabular}{|c|c|c|c|}
\hline No & Reactant & JP (N=24) & CD (N=27) \\
\hline 1 & Follower & $13 \%$ & $7 \%$ \\
\hline 2 & Process & $38 \%$ & $26 \%$ \\
\hline 3 & Organization & $29 \%$ & $26 \%$ \\
\hline 4 & Skill & $8 \%$ & $4 \%$ \\
\hline 5 & Not Identified & $13 \%$ & $37 \%$ \\
\hline
\end{tabular}

Table 5 Distribution of 'Reactants' in different publication

3.3 Distribution of Reactants for Different Catalysts

\begin{tabular}{|c|c|c|c|}
\hline No & Type of Reactants & CL (36) & CP (44) \\
\hline 1 & Follower & $26 \%$ & $0 \%$ \\
\hline 2 & Process & $12 \%$ & $41 \%$ \\
\hline 3 & Organisation & $41 \%$ & $26 \%$ \\
\hline 4 & Skills & $18 \%$ & $4 \%$ \\
\hline 5 & Not Identified & $3 \%$ & $29 \%$ \\
\hline
\end{tabular}

Table 6 Distribution of 'Reactants' for different 'Catalyst'

The distribution of 'Reactants' catalysed by Leader and Process separately are summarised in Table 6. The most frequently assigned reactant for transformation catalysed by Leaders is Organisation followed by Follower. For transformation catalysed by Process, the most frequently assigned Reactant is Process followed by Organisation. The figure below illustrates the transformations separately catalysed by Leader on Follower and on Organisation.

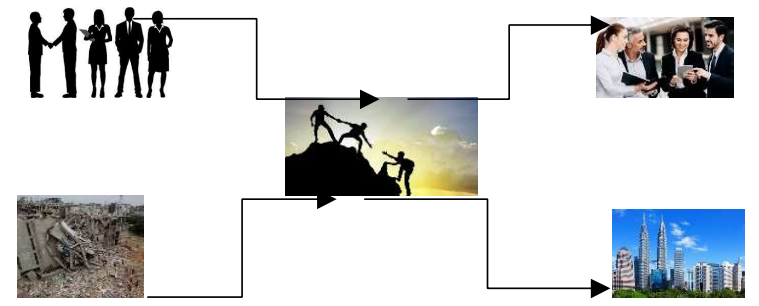

\section{CONCLUSION}

Catalyst related terms are being used to describe organisation related transformations. The most common reactants are Organisation, Process and Follower. The most commonly used catalysts are Process and Leader. This illustrate the importance of process improvement and leadership in driving organisation improvement. The findings indicate the significance of catalyst related terms in management documents to describe organisational transformation.

\section{REFERENCES}

[1] Joiner, W.B \& Josephs, S. A. (2006). Leadership Agility: Five Levels of Mastery for Anticipating and Initiating Change: Jossey Bass.

[2] Veiseh, S., Shiri, A. \& Eghbali, N. (2014). A study on ranking the effects of transformational leadership style on organisational agility and mediating role of organisational creativity. Management Science Letters, $4: 2121-2128$.

[3] Mwangi, C. I., Mukulu, E., \& Kabare, K., (2011). The Significance of Emotional Intelligence in Transformatioal Leadership for Kenyan Public Universities. International Journal of Humanities and Social Science, 1(7):28-39.

[4] Auvinet, C. \& Lloret, A., (2011). Catalytic Innovation as a strategy for social change and economical success. The case of Mexico. Cuadernos de Estudios Empresariales, 21:115-135.

[5] Karahalios, K. G, (2004). Social Catalysts: Enhancing Communication in Mediated Space. PhD Thesis. Massachusetts Institute of Technology.

[6] Mirkamali, S. M., Thani, F. N., \& Alami, F. (2011). Examining the role of transformational leadership and job satisfaction in the organizational learning of an automotive manufacturing company. Procedia - Social and Behavioral Sciences, 29:139- 148

[7] Luke, J.S. (1998). Catalytic Leadership: Strategies for an Interconnected World. San Francisco: Jossey-Bass.

[8] Kevin M. Zachery (2011). The Leadership Catalyst: A New Paradigm for Helping Leadership Flourish in Organisation. PhD Thesis. University of Pennsylvania. USA.

[9] Collins, J. (1999). Turning goals into results: The power of catalytic mechanisms. Harvard Business Review, 77(4):70-82.

[10] Novkovic, S. (2004). "Turning Goals into Results. The Power of Co-operative Principles: A Reflection on Jim Collins's Catalytic Mechanism". The International Journal of Co-operative Management, 1:56-60.

[11] Nordin, M.R, 2014. Mangkin Tindakbalas Kimia dan Pengukuhan Institusi. Penerbit Universiti Malaysia Pahang, Malaysia.

[12] Hsieh, H. F., \& Shannon, S. E, (2014). Three Approaches to Qualitative Content Analysis. Qualitative Health Research, 15 (9):1277-1288. 